\title{
Las exposiciones de la Academia de San Fernando. Espacios y prácticas de saber artístico y sociabilidad
}

The Exhibitions of the Academy of San Fernando. Places and Practices of Artistic Knowledge and Sociability Álvaro Molina UNED 


\section{RESUMEN}

La celebración de exposiciones temporales en la Real Academia de San Fernando durante la segunda mitad del siglo XVIII constituyó un nuevo espacio de conocimiento sobre las bellas artes para el público. Los visitantes tenían la oportunidad de descubrir las colecciones artísticas y tesoros de la institución, así como ver los avances realizados por aquellos profesores, alumnos y otros aficionados interesados en enseñar sus últimos trabajos. Estas exposiciones determinaron al mismo tiempo nuevas prácticas y experiencias en torno a la percepción de las obras de arte y el fomento de una incipiente crítica artística en los debates de la opinión pública.

Palabras clave

Exposiciones de arte, Academia de San Fernando, Visitantes de museos, Historia de los museos, Sociabilidad.

\section{Abstract}

The celebration of temporary exhibitions in the Royal Academy of San Fernando throughout the second half of $18^{\text {th }}$ century constituted a new place for fine art connoisseurship for the public. Visitors had the opportunity to discover the institution's art collection and treasures, as well as following the progress made by its professors, students and other amateurs interested in exhibiting their latest artworks. These exhibitions determined, at the same time, new forms of practicing and experiencing surrounding the perception of the artworks. This process came along with the promotion of an emergent art criticism in public opinion debates.

KeY WordS

Art exhibitions, Academy of San Fernando, Museum visitors, History of museums, Sociability.

Recibido: 16 de enero de 2020. Aceptado: 10 de marzo de 2020.

Esta investigación se ha desarrollado en el marco del proyecto I+D HAR2016-78098-P, financiado por la Agencia Estatal de Investigación (Ministerio de Ciencia, Innovación y Universidades) y el Fondo Europeo de Desarrollo Regional (FEDER). 
La institucionalización del saber artístico en la España de las Luces a través de las academias no sólo generó nuevas dinámicas en torno a la teoría y práctica de las bellas artes y la formación de los artistas — razón principal de su existencia—, sino también un espacio clave de conocimiento y sociabilidad. En lo que respecta a la primera cuestión, la del conocimiento, no parece necesario insistir en que, desde la fundación en 1752 de la Real Academia de las Tres Nobles Artes de San Fernando ${ }^{1}$, rectora de las que se crearían más tarde fuera de Madrid, el ámbito académico definió el canon normativo del lenguaje artístico en todo el territorio de la monarquía, contribuyendo asimismo a modelar la educación de clientes, mecenas, coleccionistas y aficionados en materia de buen gusto, es decir, un amplio público con deseos cada vez mayores de instruirse, aunque nunca dejara de ser minoritario ${ }^{2}$. Con relación a la segunda cuestión, la de la sociabilidad, quizás sí es oportuno recordar que las academias creadas durante la centuria siempre fueron lugares de reunión, asociación y disfrute. La mayor parte de ellas surgió de tertulias informales caracterizadas por el intercambio de ideas y la conversación ${ }^{3}$, abarcando más pronto que tarde otro tipo de prácticas de sociabilidad. En el caso de las academias de bellas artes, esto significó la participación de agentes y públicos más amplios y diversos, siendo una de las muchas actividades de ocio y entretenimiento de la vida moderna.

Así sucede con la organización de las exposiciones, una dinámica habitual en la vida de estas instituciones que se registra desde prácticamente sus inicios en actos reservados a sus miembros y personas de mayor distinción, pero que evolucionarían hasta convertirse en un acontecimiento de afluencia masiva de

1 Para una aproximación de conjunto a su historia y funcionamiento, sigue resultando clave el estudio de Claude Bédat, La Real Academia de Bellas Artes de San Fernando (1744-1808). Contribución al estudio de las influencias estilísticas y de la mentalidad artística en la España del siglo XVIII, Madrid, FUE, 1989.

2 Daniel Crespo Delgado, «Enseñanza de la Historia del Arte. Orígenes e Ilustración», Imafronte, 24 (2015), págs. 43-72; pág. 58.

3 Eva Velasco Moreno, «Nuevas instituciones de sociabilidad: las academias de finales del siglo XVII y comienzos del XVIII", Cuadernos Dieciochistas, 1 (2000), págs. 39-55; para una revisión comparativa de estas tempranas academias con la de San Fernando y las relaciones políticas y sociales de sus miembros, véase, en este mismo monográfico, Jacques Soubeyroux, «La Real Academia de San Fernando y la construcción de un campo de las Bellas Artes en España en el siglo XvIII», Cuadernos de Estudios del Siglo XVIII, 30 (2020), págs. 593-607. 
gentes de toda clase y condición, cuando se empezó a forjar la noción moderna del público en España, ya en los albores del nuevo siglo ${ }^{4}$. Entre un extremo y otro, las exposiciones organizadas por la Academia de San Fernando durante sus primeros cincuenta años de vida — objeto de esta investigación- ayudaron a canalizar el interés por las bellas artes de aficionados, viajeros y forasteros, así como a perfilar la imagen de la institución en la opinión pública. A estas cuestiones nos acercaremos a través de la documentación de archivo conservada en la propia Academia, la publicación de sus actas y memorias, y las noticias a las que podía acceder el lector curioso de la época en prensa, guías y otras obras similares ${ }^{5}$.

\section{Las primeras exposiciones. Concursos de «lucida concurrencia»}

La presencia de aficionados en el seno de la Academia de San Fernando se remonta a la etapa inicial de la denominada «Junta preparatoria» entre 1744, cuando el rey Felipe $\mathrm{V}$ decidió apadrinar la creación de un establecimiento público destinado a la enseñanza de la pintura, la escultura y la arquitectura, y 1752, fecha de su fundación oficial bajo el reinado de Fernando VI. A juzgar por la documentación conservada ${ }^{6}$, ya en la primera junta pública, celebrada el 1 de septiembre de 1744 en las dependencias del palacio nuevo, se animó a sus miembros, caballeros y profesores a abrir el círculo de asistentes a la solemne reunión, invitando a aquellos aficionados que juzgasen conveniente entre sus amistades, o entre aquellas personas distinguidas de las que tuvieran noticia:

Estando resuelto, y aprobado, el que mañana martes 1 de septiembre se celebre la primera Junta general y pública de la Real Academia de Pintura, Escultura y Arquitectura, y se dé principio a los estudios formales de ella; se lo participo a

4 Sobre las cualidades y orígenes de este incipiente sujeto colectivo, existente en Europa con varias décadas de antelación, véanse Thomas E. Crow, Pintura y sociedad en el París del siglo XVIII, Madrid, Nerea, 1989, y Jesús P. LoRENTE, «Art in the urban public sphere: art venues by entrepreneurs, associations and institutions, 1800-1850», en Peter Borsay y Jan Hein Furnée (eds.), Leisure cultures in urban Europe, c. 17701870. A transnational perspective, Manchester, Manchester University Press, 2016, págs. 21-48.

5 El fenómeno de estas exposiciones, particularmente en su periodo de consolidación desde principios del siglo xix, ha sido estudiado por Esperanza Navarrete Martínez, La Academia de Bellas Artes de San Fernando y la pintura en la primera mitad del siglo XIX, Madrid, FUE, 1999, págs. 297-327.

6 Como es sabido, el proyecto de una academia pública patrocinada por la corona surgió, tras varios intentos previos, al hacerse cargo el monarca de la iniciativa que había puesto en marcha tres años antes en su taller particular el escultor Giovanni Domenico Olivieri. La documentación completa de esta primera etapa de la historia de la institución se encuentra catalogada y descrita en Esperanza Navarrete Martínez, Catálogo documental de la Junta preparatoria de la Real Academia de Bellas Artes de San Fernando (1744-1752), Madrid, Real Academia de Bellas Artes de San Fernando, 2007. 
V. S. para que mañana a las seis y media de la tarde se sirva de concurrir a la mencionada Junta general que se convoca en la Casa del Rey, en que habita el Director de ella, y en donde se celebraron las dos primeras Juntas; y respecto de ser esta pública, podrá V. S. convidar a algunos de los caballeros, y Ministros aficionados que fuesen de su satisfacción ${ }^{7}$.

La sala donde se había llevado a cabo el acto era la misma en que se habían celebrado poco tiempo atrás las dos primeras juntas, pero en esta ocasión se le «había dado mayor extensión» y su adorno formaba «un teatro muy vistoso y lucido, siendo correspondiente a su capacidad el numeroso concurso de caballeros, y ministros convidados, y de los discípulos de las tres artes, entre los cuales hay algunos que pueden legítimamente aspirar al título, y ejercicio de Maestros». Una vez concluida la discusión de los acuerdos a tratar, el verdadero reclamo de la reunión se encontraba en la demostración que se había hecho preparar a continuación; así, pues,

[...] bajaron todos al salón en que ya estaba colocado el modelo vivo, por disposición del Director general, en una postura muy arrogante, caprichosa y pintoresca; y empezaron los Maestros, y Discípulos (que pasaban de cincuenta) a copiar del natural, los Pintores con el lápiz, y los Escultores con el barro, y todos con tanta aplicación, y gusto, que quedó muy adelantada la figura, así de relieve, como de dibujo ${ }^{8}$.

La misma fórmula se repitió un año más tarde, ya trasladado el establecimiento a la nueva sede de la Real Casa de la Panadería en la Plaza Mayor de la Villa. En esta ocasión, la asamblea se amenizó con música — costumbre desde entonces habitual en este tipo de ceremonias - y, tras celebrarse la función de la junta pública, el «grande concurso, que apenas le podían contener los anchurosos salones, y piezas del nuevo Sitio» se trasladó al llamado «salón de los estudios de la Pintura y Escultura», donde se dispuso un grupo de dos modelos para ser copiado por maestros y discípulos. A diferencia del año anterior, la academia contaba ya con casi un año de actividad, lo que permitió exhibir por primera vez al público invitado a la junta las obras de sus profesores más distinguidos:

\footnotetext{
7 Archivo de la Real Academia de Bellas Artes de San Fernando, Madrid (ARABASF), «Oficio de Fernando Triviño (viceprotector) al conde de Salceda y a Baltasar Elgueta (caballeros académicos) convocándoles a la junta general y pública de 1 de septiembre», 31 de agosto de 1744, Sig. 1-1-1-49. En el oficio remitido el mismo día a los «maestros directores de las tres artes», se les informaba que podrían llevar igualmente a «algunos de los discípulos, o aficionados» que fuesen también «de su satisfacción» (Sig. 1-1-1-50).

8 ARABASF, «Relación de lo ejecutado en la primera Junta general, pública y preparatoria de la Real Academia de pintura, escultura y arquitectura», 2 de septiembre de 1744, Sig. 1-1-1-56.
} 
El adorno de este salón igualaba, si no excedía, al del otro en que se celebró la Junta, aunque por muy diverso modo, y gusto, aumentando el que tenían los concurrentes la especialidad notable de ver ya rodeadas sus paredes de muchos, y excelentes dibujos y modelos de barro de los Maestros Pintores y Escultores que han tenido en estos diez meses la dirección de ambas artes, y merecido que sus obras se expongan al público para la enseñanza de los discípulos, y aficionados ${ }^{9}$.

Es bastante probable que las obras expuestas en este salón continuaran decorando la estancia en lo sucesivo, pero todo parece indicar que únicamente los asistentes a la junta pudieron verlas ya que no consta ninguna apertura posterior al público. En lo que respecta a la demostración de los alumnos, debió ser algo bastante excepcional, limitándose, que sepamos, a estas dos juntas públicas de 1744 y 1745 , así como una práctica similar en la ceremonia del 13 de junio de 1752 celebrada con motivo de la «abertura solemne» de la Academia en el acto de su fundación oficial. Esta vez, «siete jóvenes dispuestos a hacer repentina prueba de sus habilidades» se dispusieron a «modelar y dibujar una estatua de Mercurio volante, colocada desde el principio en medio del circo de la Academia», una solución que no solo resultó más decorosa al prescindir de un modelo vivo desnudo a la vista de toda la concurrencia ${ }^{10}$, sino que debió facilitar la propia organización del acto, pues «mientras estos jóvenes trabajaban, continuó la música, y se sirvió un refresco con el mejor orden, y abundancia» ${ }^{11}$. La Gaceta de Madrid, al relatar la función, explicaba que las «producciones de las artes» de estos siete jóvenes se mezclaba con las de «la poética, castellanas, y latinas, de algunos ingenios de la Academia», mereciendo toda la demostración

[...] el aplauso de todo el lucido, y numeroso concurso, que se componía, no sólo del Cuerpo de la Academia, y sus Excmos. e Ilmos. Vice-Protector, Consiliarios, Académicos de Honor, Directores, Maestros de las tres Artes, Profesores, y Discípulos; sino también de un gran número de personas de la mayor distinción,

9 ARABASF, «Oficio de Fernando Triviño dirigido al marqués de Villarías (protector de la academia)», 16 de julio de 1745, Sig. 1-1-2-45.

10 Conviene recordar que la entrada a las sesiones de dibujo estaba reservada a los discípulos, profesores y miembros de la academia, así como a aquellos aficionados distinguidos autorizados por la Academia, tal y como se ordenaba en sus estatutos. Según el artículo XVIII, era responsabilidad de los porteros «no permitir la entrada sino a los Académicos, a los discípulos y personas distinguidas» en las «horas de los estudios de la noche», que era el momento en que acudían los modelos vivos a posar. También estaba prohibida la venta y compra de «dibujos, cuadros, o modelos de la Academia» bajo pena de cincuenta ducados; Estatutos de la Real Academia de S. Fernando, Madrid, Casa de Gabriel Ramírez, 1757, pp. 49-50 y 87.

11 Se trataba de los dibujantes Isidro Carnicero, José Dussent y Francisco Díaz, y los escultores José López y Manuel Suárez: Abertura solemne de la Real Academia de las Tres Bellas Artes, Pintura, Escultura y Arquitectura, con el nombre de San Fernando, Madrid, Casa de Antonio Marín, 1753, págs. 15-16. 
recomendables en la República literaria, quienes admiraron la magnificencia del Rey, nuestro Señor, y el amor con que cuida, que en todas Ciencias, y Artes hagan sus vasallos los mayores progreso ${ }^{12}$.

Por la descripción que se hace de los invitados en esta y otras relaciones, debemos suponer que en estos primeros años no hubo cabida para las mujeres en las juntas públicas de la institución, y menos aún en las sesiones de trabajo con modelos vivos posando. Esta última práctica estaba, además, vetada para las propias artistas, quienes por una cuestión de honor propia de su sexo no podían formarse en el estudio de la anatomía, a diferencia de los artistas varones ${ }^{13}$. Esto último no impidió, sin embargo, que muchas ingresaran como académicas de mérito, y algunas llegaran a ser nombradas directoras honorarias, como sucedió en la Academia de San Fernando desde sus primeros años de vida ${ }^{14}$. De cualquier modo, lo evidente es que los escenarios de trabajo y sociabilidad de la Academia siguieron siendo esencialmente masculinos ${ }^{15}$.

Uno de los espacios a los que las mujeres sí debieron acceder desde el principio fue el de las exposiciones públicas, abiertas a toda clase de visitantes, aunque no hemos llegado a ver ningún testimonio que explicite su presencia. Su organización estuvo directamente ligada a los premios generales que la Academia convocó desde 1753 para impulsar la carrera de jóvenes artistas en los ámbitos de la pintura, la escultura, la arquitectura y el grabado. Se trataba de un concurso al que podían presentarse tanto los discípulos de la institución como opositores venidos de otras ciudades y provincias, para cuya difusión se hacían imprimir y colgar en lugares públicos edictos describiendo las bases y normas. Su periodicidad fue al principio anual, y cada tres años a partir de 1757 ,

12 Gaceta de Madrid, 13/06/1752, núm. 24, págs. 203-204.

13 Esto último constituyó una de las brechas más claras entre hombres y mujeres en la formación académica, siendo una práctica común en toda Europa; Álvaro MoLina, Mujeres y hombres en la España ilustrada. Identidad, género y visualidad, Madrid, Cátedra, 2013, págs. 247-256.

14 En estos casos su ausencia era notoria no solo en las salas de dibujo al natural, sino también en las reuniones de las juntas a las que tenían derecho a ir, a las cuales renunciaban igualmente por una cuestión de pundonor; Ann Theresa Sмгтн, The Emerging Female Citizen. Gender and Enlightenment in Spain, Berkeley, University of California Press, 2006, pág. 59. Los expedientes de las socias académicas, reunidos en el legajo de «Señoras Académicas. Desde 1773 a 1821», ARABSF, Sig. 1-40-4, han sido recientemente transcritos por Mariángeles PÉrez-Martín, «Ilustres e ilustradas. Académicas de Bellas Artes en España (ss. XVIII-XIX)», Tesis Doctoral, Valencia, Universitat de València, 2018, t. II.

15 La primera vez que consta la presencia de mujeres en una junta pública fue en la entrega de premios de 1790, a la que fueron invitadas las «Señoras Académicas y la Sociedad [Junta] de Damas»; Distribución de los premios concedidos por el Rey Nuestro Señor a los discípulos de las Nobles Artes [...] en la Junta Pública de 4 de agosto de 1790, Madrid, Imprenta de la Viuda de Ibarra, pág. 50. La Junta de Damas estaba formada por las socias de la Real Sociedad Matritense de Amigos del País, constituida tres años antes como un cuerpo independiente de la misma; Sмгтн, The Emerging Female Citizen, págs. 50-73. 
de acuerdo a los estatutos publicados entonces ${ }^{16}$. Desde su primera edición, la entrega de los premios fue concebida como una ceremonia pública de carácter solemne, a la que asistían tanto los miembros de la academia, discípulos y artistas concursantes como «la mayor parte de la Grandeza, Ministros extranjeros, y personas de primera distinción». Dado el elevado número de asistentes y la necesidad de mostrar las obras presentadas, durante los primeros años se buscaron locales más amplios que la sede de la Real Casa de la Panadería. Así, pues, en 1753 el rey cedió el cuarto bajo del palacio nuevo, decorado para la ocasión del siguiente modo:

Las paredes de este gran Salón se adornaron con damascos, cornucopias, y principalmente con pinturas, y bajorrelieves de los Directores, y miembros de la Academia. En la Sala inmediata se pusieron los cuadros, bajorrelieves, y diseños de los Opositores de la primera clase de todas las Artes. En la segunda los trabajos de los de la segunda clase; y en la tercera los de la última, todos en la misma disposición que se pusieron para hacer el juicio de su mérito. Las demás Salas hasta la salida tenían el adorno correspondiente ${ }^{17}$.

Según la breve nota aparecida en la Gaceta de Madrid, la sesión estuvo presidida por José de Carvajal en calidad de Protector, y contó con la «asistencia de sus Excmos. e Illmos. Consiliarios, toda la Grandeza, Ministros Extranjeros, y el más lucido, y numeroso concurso», distribuyéndose «por la primera vez los diez y ocho Premios que el Rey había destinado a los más hábiles Profesores de las tres Nobles Artes». La noticia no hacía, sin embargo, mención alguna a la organización posterior de la exposición, adelantando solo que la Academia daría «una relación circunstanciada» del acontecimiento ${ }^{18}$. Dicha relación dio pie a las actas publicadas bajo el título genérico de Distribución de premios, cuyas páginas daban cabida a las memorias de actividades de la propia institución entre una ceremonia y la siguiente. En la primera de todas ellas, la crónica relativa a la entrega de premios explicaba que el concurso de «grandeza, y personas de la más elevada esfera» fue «el más numeroso que en funciones de este género se

${ }^{16}$ Historia y Alegoría: los concursos de pintura de la Real Academia de Bellas Artes de San Fernando (1753-1808), Madrid, Real Academia de Bellas Artes de San Fernando, 1994, págs. 15-22; Hacia una nueva idea de la arquitectura. Premios generales de Arquitectura de la Real Academia de Bellas Artes de San Fernando, Madrid, Comunidad de Madrid, 1992, págs. 32-38.

17 Relación de la distribución de los premios concedidos [...] en la Junta general celebrada en 23 de diciembre de 1753, Madrid, Oficina de D. Gabriel Ramírez, págs. 12-13. La clasificación de las obras por sus respectivas categorías se mantuvo como criterio expositivo durante los siguientes años, aunque no siempre se dispone de una descripción tan detallada respecto al número de salas empleadas y su ubicación.

18 Gaceta de Madrid, 25/12/1753, núm. 52, págs. 415-416. 
ha visto; pues sin embargo de la amplitud del teatro faltó lugar para muchas» personas,

[...] en cuya atención, y para que el público tuviese la satisfacción de ver los progresos de la Academia, de orden de Su Excelencia se conservaron desde el expresado domingo 23 de diciembre, hasta el 6 de enero de este año, en los mismos Salones, no sólo los trabajos de los Opositores, sino es todo el ornato que sirvió el día de la función. Y el público ha recibido con tan general admiración, y aplauso estas primicias de la Academia, que en los quince días que estuvieron expuestas atrajeron un excesivo número de gentes de todas clases: de modo, que sin embargo de abrirse desde las nueve de la mañana hasta la una, y desde las tres de la tarde hasta puesto el sol, fue la concurrencia tan grande en el último como en el primer día ${ }^{19}$.

Como sucede hoy en día, el éxito de la exposición se midió por la altísima afluencia de visitantes que, durante las dos semanas de apertura, accedieron a ver las obras de discípulos y profesores, aunque no debemos descartar la enorme curiosidad que debía suponer para la mayoría de esas gentes acceder, posiblemente por vez primera, al interior de la fábrica del palacio nuevo. También hay que pensar en la novedad que representaba el evento en una ciudad en la que todavía no se había llegado a experimentar ni por asomo la oferta cultural y científica que se llegaría a alcanzar en las siguientes décadas. Fuera como fuese, la dinámica se mantuvo desde entonces de modo similar. Para la distribución de premios del año siguiente, se facilitó a la Academia el teatro del Real Seminario de Nobles, donde se celebró la junta pública el 22 de diciembre de $1754^{20}$ : allí se exhibieron, con el fin de adornar «con toda magnificencia aquel gran teatro»,

[...] varias obras de profesores de la Academia, singularmente el retrato de mármol de S. M. y la Medalla también de mármol del señor Don José de Carvajal, que en conformidad de lo acordado en 6 de junio presentó concluidas para este día Don Juan Domingo Olivieri, y el retrato de pintura de S. Exc. que según el mismo acuerdo ha ejecutado D. Andrés de la Calleja, cuyas obras atrajeron la atención y los aplausos del público, que las juzgó dignas de los grandes créditos de sus autores ${ }^{21}$.

Prueba del éxito que había tenido el año anterior la exposición, y la utilidad que la Academia concedía a esta práctica para dar a conocer sus progresos,

19 Relación de la distribución de los premios, págs. 69-70.

20 Historia y Alegoría, pág. 41.

${ }^{21}$ Distribución de los premios concedidos [... ] en la Junta general de 22 de diciembre de 1754, Madrid, Oficina de Gabriel Ramírez, 1755, pág. 19. 
fue la decisión de hacer trasladar unos días más tarde las obras reunidas en el Seminario de Nobles para la junta pública a la sede de la propia institución, con el fin de organizar allí la muestra:

Desde el día 25 del mismo mes se expusieron en las salas de la Real Casa de la Panadería, donde reside al presente la Academia, así las nuevas obras de sus directores, como todas las de los que concurrieron a los premios, y en los quince días siguientes, en que estuvieron a todas horas abiertas sus puertas, fue numeroso el pueblo que concurrió a reconocer y celebrar los progresos y adelantamientos de los discípulos; quedando todos tan gozosos de estas ventajas, como reconocidos a la gran piedad del Rey autor de ellas ${ }^{22}$.

La ceremonia de entrega de premios correspondiente a 1755 siguió la misma senda, valorándose cada vez más el papel de estas exposiciones para proyectar la imagen de la Academia y su utilidad pública. En esta ocasión, el acto se retrasó hasta el mes de enero del año siguiente, deseando la Academia «que esta solemnidad se hiciese en sitio, no solo autorizado, sino de fácil acceso al público, donde este pudiese ver con satisfacción las obras de la Academia»: es decir, ya no solo se precisaba un espacio adecuado al decoro de las autoridades presentes en la ceremonia, sino apropiado para acoger posteriormente a los visitantes de la exposición. El lugar elegido para ello fue las Casas Consistoriales del Ayuntamiento de Madrid. Una vez allí, y siguiendo la costumbre, «se adornó el Salón principal, y se pusieron en él varios cuadros de Individuos de la Academia. Y en el inmediato los trabajos de pensado, y de repente, de los Opositores y de otros Profesores» ${ }^{23}$. Tras la ceremonia, y

[...] desde el día siguiente lunes 26 de enero estuvieron expuestas en los mismos salones de las Casas Consistoriales, así las nuevas obras de Pintura y Escultura de algunos individuos de la Academia, como las de los Opositores. Y en los doce días siguientes concurrieron muchísimas personas de todas clases a reconocer y celebrar el adelantamiento de los Discípulos ${ }^{24}$.

22 Distribución de los premios [...] de 1754, págs. 89-90.

${ }_{23}$ Distribución de los premios concedidos [...] en la Junta general de 25 de enero de 1756, Madrid, Oficina de Gabriel Ramírez, pág. 15. La novedad de este año fue la eliminación del refresco que solía ofrecerse a los invitados «conociendo por la experiencia de los años antecedentes los grandes embarazos que ha ocasionado y que se inutiliza cuando en él se expende», acordándose «de unánime consentimiento que en adelante en Junta alguna Pública ni privada la Academia no dé ni haga servir más refrescos»; Junta ordinaria de 2 de diciembre de 1755, citado en Historia y Alegoría, pág. 51.

24 Distribución de los premios [...] de 1756, págs. 47-48. 
Las Casas Consistoriales acogieron de nuevo la ceremonia y posterior exhibición en 1757, en cuyos «salones quedaron expuestas los ocho días siguientes las obras de los profesores, a cuya vista y admiración concurrió el Público con la misma satisfacción que en los años precedentes» ${ }^{25}$. La escueta referencia realizada en la descripción del acto de este año permite comprobar cómo el factor de novedad de las primeras ediciones de los premios iba perdiendo impacto hasta para los propios organizadores, cuando los premios empezaron a convocarse cada tres años. La siguiente edición, cuya ceremonia tuvo lugar el 28 de agosto de 1760, se celebró ya bajo el reinado de Carlos III, desarrollándose por primera vez el acto en la «Real casa de su residencia» de la Plaza Mayor, tras haberse hecho una ampliación del «principal salón con las oportunas comunicaciones que se le abrieron al interior y a las galerías, [donde] se colocaron los asientos convenientes para un concurso muy numeroso». Sobre la muestra, sin embargo, apenas se mencionaba que las obras «permanecieron expuestas al público en los Salones y Galerías, y concurrieron a verlas muchas personas de todas clases» ${ }^{26}$.

Durante las siguientes ediciones, la noticia de las exposiciones descrita en las actas o memorias que la institución publicaba en cada Distribución de premios fue perdiendo, salvo algunas excepciones, la riqueza de detalles de los primeros años, aunque en algunas ocasiones se tuviera que ampliar el periodo de apertura más allá de las dos semanas habituales por la alta afluencia de visitantes que acudía a ver las obras, como sucedió en 1763 y 1766. En el primer caso, había «sido tan numeroso el concurso de toda clase de personas a celebrarlas, que fue preciso tenerlas de manifiesto todo el mes de julio» ${ }^{27}$; en el segundo, se explicaba que «Madrid todo manifestó el placer que le resulta de ver tantos y tan insignes progresos en las artes, concurriendo por mañana y tarde en excesivo número a admirar sus obras: cuyo agradable espectáculo se le conserva por todo el presente mes de agosto» ${ }^{28}$. Parece que en 1769 no fue preciso ampliar el plazo de apertura pública, aunque se mantuviera un alto número de visitantes:

[...] desde el 17 del mismo mes de julio se expusieron a la pública censura las obras de los Opositores, y muchas otras de varios individuos y discípulos de la Academia, con el mismo orden y mérito que estuvieron colocadas el miércoles 12

25 Distribución de los premios concedidos [...] en la Junta general de 6 de febrero de 1757, Madrid, Oficina de Gabriel Ramírez, pág. 40.

26 Distribución de los premios concedidos [...] en la Junta general de 28 de agosto de 1760, Madrid, Oficina de Gabriel Ramírez, págs. 28-29 y 67.

${ }_{27}$ Distribución de los premios concedidos [...] en la Junta general de 3 de junio de 1763, Madrid, Imprenta de Gabriel Ramírez, 1763, pág. 100.

28 Distribución de los premios concedidos [...] en la Junta General de 3 de agosto de 1766, Madrid, Imprenta de la Viuda de Eliseo Sánchez, 1766, pág. 76 
del propio mes [día de la ceremonia]. Todo Madrid ha manifestado mucho placer de los adelantamientos de las Artes en un continuo concurso por mañana y tarde, admirando tan dilatados progresos ${ }^{29}$.

El traslado de la Academia al edificio de la calle de Alcalá en 1773 y las obras que hubo que acometer en el mismo para instalarse provocó la suspensión de los premios de 1775, retomándose la actividad tres años más tarde, en $1778^{30}$. Sorprende que el nuevo establecimiento, cuya noticia se celebraba en la Distribución de los premios de este último año, no fuese motivo de comentario alguno en la memoria al mencionar las exposiciones, limitándose únicamente a indicar que, tras la celebración de la ceremonia de entrega de premios, se dio la orden «de que las obras de los Opositores quedasen expuestas al público por espacio de quince días» ${ }^{31}$.

Sí ocupó más espacio en las memorias publicadas aquel año uno de los actos más celebrados por sus miembros: la visita personal del monarca Carlos III, que se describía en estos términos:

Lo que sin duda excedió los límites de su benignidad, fue la determinación de venir personalmente a esta casa, como se verificó en 30 de diciembre de 1775, en cuya ocasión se dignó S. M. recorrer todas las Salas de Estudios, observando, preguntando, y complaciéndose de cuanto vio, y del celo con que este distinguido Cuerpo se esmera en que tengan efecto sus paternales intenciones por medio de tan útil establecimiento ${ }^{32}$.

${ }^{29}$ Distribución de los premios concedidos [...] en la Junta General de 12 de julio de 1769, Madrid, Imprenta de la Viuda de Eliseo Sánchez, 1769, págs. 57-58.

30 Uno de los motivos de buscar una nueva sede fue, precisamente, las limitaciones cada vez mayores de la Real Casa de la Panadería, no solo por necesidades de ampliar los espacios de enseñanza, sino también para acoger adecuadamente la celebración de juntas públicas y exposiciones; Juan José MarTín GonZÁLEz, "La distribución del espacio en el edificio de la antigua academia», Academia. Boletín de la Real Academia de Bellas Artes de San Fernando, 75 (1992), págs. 163-210; pág. 166.

31 Distribución de los premios concedidos [...] en la Junta pública de 25 de julio de 1778, Madrid, Joaquín Ibarra, 1778, pág. 78. Las precisiones anotadas en los libros de actas tampoco aportan mucha más información para conocer, por ejemplo, qué salas en concreto se ocuparon para este fin: «Igualmente quedó resuelto que las obras de los opositores queden expuestas según costumbre en las salas de la Academia, debiendo estar abiertas los quince días siguientes, desde las nueve de la mañana hasta las doce; y desde las cuatro de la tarde hasta las siete»; ARABASF, «Actas de sesiones particulares y de gobierno de la Real Academia de Bellas Artes de San Fernando, 1757-1854», Junta pública de 25 de julio de 1778, Sig. 3-84, fol. 100r.

32 A emulación del rey, dos días más tarde hicieron lo propio el Príncipe de Asturias y sus dos hermanos, los infantes Antonio y Gabriel: «Una época tan feliz para la Academia se hizo señalada, no solamente por la presencia de S. M., sino por la del Príncipe nuestro Señor, y de los Señores Infantes D. Gabriel, y D. Antonio, que siguiendo las pisadas de su Augusto Padre, se dignaron a venir a ella, y manifestar particular gusto y complacencia en cuanto vieron el día primero de enero de 1776»; Distribución de los premios [...] de 1778, págs. 22-23. 
Lógicamente, y a diferencia de otros muchos acontecimientos solemnes en la vida de la Academia, como el de su abertura, la visita del rey fue recogida en las páginas de la Gaceta de Madrid en una extensa descripción que, sin embargo, tenía como principal fin dar noticia de la instalación del Gabinete de Historia Natural en la segunda planta del edificio ${ }^{33}$ :

Dignose S. M. de honrar no solo aquel museo, sino también a la misma Academia, con haber pasado el sábado 30 de diciembre último a las 9 de la mañana, acompañado del Señor Infante D. Luis, a visitar personalmente ambos establecimientos, dejando así autorizado el del Gabinete que destina a la instrucción pública, y alentando a su Academia para continuar con tan poderoso fomento el ejercicio de las Artes de su instituto. Después de haber visitado el rey las salas de ésta, y haberse enterado muy por menor de los estudios que a cada una de ellas correspondían, distinguiendo a todo el cuerpo con las más benignas demostraciones de lo satisfecho que se hallaba del celo de sus individuos, subió S. M. al Gabinete de Historia Natural [...] y a las 11 se restituyó S. M. a palacio, dando a su regreso nuevas muestras de la aprobación que le merecían los progresos de la Academia, y los felices principios del Gabinete ${ }^{34}$.

De la descripción de la noticia se pueden subrayar dos aspectos; en primer lugar, que el público de la época pronto reconoció el edificio de la calle de Alcalá como un lugar en el que convivían dos instituciones ligadas entre sí, no sólo por estar ambas bajo la misma protección real o la idoneidad de compartir un espacio, sino también por el propio modo de concebir el saber ilustrado, pues a nadie podía extrañar reunir bajo un mismo techo el estudio de las ciencias y las $\operatorname{artes}^{35}$; y así se leía, de hecho, en la inscripción que recibía al visitante en letras de bronce, ideada por Tomás de Iriarte: «Carolus III. Rex Naturam, et Artem sub uno tecto in publicam utilitatem consociavit. ANNO MDCCLXXIV» ${ }^{36}$. En segundo lugar, el texto dejaba muy clara la misión principal que prevalecía en cada establecimiento: a la Academia correspondía «fomentar el ejercicio de las artes» mientras que el Gabinete tenía como principal cometido servir a «la instrucción pública», por encima de generar conocimiento científico, actividad

$33 \quad \mathrm{M}^{\mathrm{a}}$ de los Ángeles Calatayud Arinero, «Antecedentes y creación del Real Gabinete de Historia Natural de Madrid», Arbor, 482 (1986), págs. 9-34, pág. 22.

34 Gaceta de Madrid, 02/01/1776, núm.. 1, págs. 7-8

35 La creación de una academia de ciencias y artes fue, de hecho, una de las ideas que más propuestas generó durante toda la centuria, como ha estudiado recientemente Helmut C. JACOBS, «Utopías de la organización e institucionalización de las artes y las ciencias en la época de la Ilustración: los proyectos de fundación de academias», Anejos de Dieciocho, 5, Spring (2019), págs. 141-161.

36 Jesusa VEGA, Ciencia, arte e ilusión en la España ilustrada, Madrid, CSIC-Ed. Polifemo, 2010, pág. 38. 
que se le presuponía igualmente. Esta distinción es interesante al valorar el papel que cumplieron las exposiciones, donde primó dar a conocer al público los progresos de las bellas artes antes que otros objetivos, como podía ser el de contribuir a formar un criterio en materia de buen gusto. Para esto último, la Academia de San Fernando no disponía aún — como el Gabinete de Historia Natural — de una colección apropiada a su especialidad, salvo para cubrir las necesidades básicas en la formación de los artistas; dicho de otro modo, faltaba un «museo» que pudiera interesar, por la riqueza de sus fondos, al aficionado. Eso explica que ni siquiera Antonio Ponz, secretario de la Academia durante casi quince años y una de las figuras más preocupadas del periodo en difundir las luces en materia de bellas artes al gran público ${ }^{37}$, entrase a describir la colección artística de la institución en su Viaje de España, salvo una referencia a los fondos de estatuas antiguas, que entonces eran los que podían tener un mayor interés para el visitante ocasional ${ }^{38}$.

\section{La consolidación de las exposiciones. La expansión del «idioma de las artes»}

El hecho de que la Academia de San Fernando fuera una institución aparentemente poco atractiva para curiosos y aficionados no solo se debía al hecho de ser un establecimiento destinado primordialmente a la enseñanza de las bellas artes, sino también a la poca relevancia que, durante sus primeros años de vida, tuvo tanto en la prensa como en aquellas publicaciones y guías que daban a conocer a naturales y forasteros la corte de Madrid. Respecto a la prensa, basta recordar la poca atención que mereció la institución en la Gaceta de Madrid, apenas limitada como hemos visto a referir sus ceremonias y actos más emblemáticos. El lector que, por su lado, decidiera consultar alguna guía de la época, se encontraría en parecidas circunstancias. Un ejemplo elocuente es el Kalendario manual y guía de forasteros en Madrid, que

37 Daniel Crespo Delgado, Un viaje para la Ilustración. El Viaje de España (1772-1794) de Antonio Ponz, Madrid, Marcial Pons, 2012; véase, en especial, la tercera parte de la obra relativa a las bellas artes.

38 Según el erudito, las salas de la estrenada sede de la calle de Alcalá estaban «adornadas principalmente con pinturas, diseños, y esculturas, así de los Profesores Académicos, como de otras que se han recogido", sin entrar a precisar más detalles. Sobre la colección escultórica, explicaba que «aunque restauradas en varias partes, se hallan en esta academia diferentes yesos, o estatuas, formadas de las más célebres de la Antigüedad, como son el Hércules, la Flora, la Venus, e Gladiator, y otras muchas; habiéndose aumentado últimamente la colección de modelos con los que el rey ha regalado últimamente vaciados por los originales encontrados en el Herculano, o Real Sitio de Portici en Nápoles. Consisten en buena porción de bustos: en algunas figuras grandes; en otras más pequeñas, y bajo relieves»; Antonio Ponz, Viaje de España en que se da noticia de las cosas más apreciables, y dignas de saberse, que hay en ella, Madrid, Joaquín Ibarra, 1776, t. V, pág. 287. 
se publicaba a comienzos de año para dar información actualizada de todo lo que podían necesitar naturales y forasteros para manejarse en la corte. En sus páginas destaca la ausencia de cualquier noticia relativa a la existencia de la Junta preparatoria vigente entre 1744 y 1752 , pese a que durante esos años la actividad de la institución tuviera ya un peso evidente en la vida artística de la ciudad, formando parte además de los espacios de sociabilidad cortesana en que se movían muchos de sus miembros. Tampoco se incluyó su mención en el listado de las «Academias creadas en esta Corte bajo la Real Protección» hasta la edición del año 1758 — seis años después de su fundación-, debido seguramente a que sus estatutos definitivos no fueron sancionados por el rey hasta el año de $1757^{39}$.

De mayor interés, tanto por ser iniciativas privadas como por su diversidad, son otras dos guías publicadas en el transcurso de estos años en Madrid, las cuales nos permiten conocer la idea que se podía formar un lector al buscar información sobre la academia. En la más temprana de ellas (1763), se dice que «la Real Academia de San Fernando, de las tres Nobles Artes, de Pintura, Escultura, y Arquitectura; se junta todas las noches en el Salón de la Plaza, sobre el Peso Real, y dura su ejercicio dos horas»; esto es, hacía mención a las clases que recibían los alumnos durante la noche, subrayando su condición de institución educativa; de hecho, los datos referidos se encontraban dentro del epígrafe dedicado a la «Enseñanza pública» ${ }^{40}$. En la segunda guía, publicada veinte años después, la Academia aparecía en el listado de las «casas que más se suele necesitar saber en esta Corte, así para los Naturales como para los Forasteros», si bien es cierto que en este epígrafe no se recogían comentarios de las instituciones citadas. Eso se encontraba en otro apartado dedicado a citar los «Edificios Profanos que adornan esta Corte, con expresión del uso que en el día se hace de ellos», donde sí constaba una mención al Gabinete de Historia Natural, «en donde en varias salas están expuestas al público las más exquisitas producciones de los reinos vegetal, animal y mineral, con otras muchas curiosidades ${ }^{41}$.

Prueba del desconocimiento que existía sobre la Academia entre forasteros y viajeros recién llegados es el precioso testimonio de Joseph Townsend, que

39 Kalendario manual, y guía de forasteros en Madrid para el año de MDCCLVIII, Madrid, Antonio Sanz, 1758, [pág. 60]; Estatutos, pág. 8.

40 Manuel Isidoro SÁnchez, Madrid en la mano. Noticia cierta de las Calles, y Plazuelas de esta coronada Villa de Madrid, Madrid, Oficina de Manuel Martín, 1763, pág. 122. En el mismo apartado se recogían, no obstante, otros espacios del saber tan dispares entre sí como la Real Biblioteca Real, la oficina de la Gaceta o la ubicación de las librerías venales.

41 Manuel Alonso, Lazarillo o nueva guía para los naturales y forasteros de Madrid, Madrid, Oficina de Hilario Santos Alonso, 1783, págs. 109 y 39. 
decidió pasarse por la recomendación que le había hecho Pedro Rodríguez de Campomanes «al descubrir que no había visitado su institución predilecta». El británico se presentó allí a la mañana siguiente y se dirigió a su secretario, Antonio Ponz,

[...] una persona de buen gusto y juicio para las artes, que me acompañó en mi recorrido por las numerosas y magníficas salas que forman parte de esta institución. Volví por la tarde para ver a los estudiantes mientras realizaban sus tareas, y tuve entonces el placer de encontrar a doscientos ochenta jóvenes dibujando, a veinte dedicados al estudio de la arquitectura y a treinta y seis ocupados en el modelado de arcilla, algunos de ellos copiando vaciados y otros modelos vivos ${ }^{42}$.

En ninguna de las guías antes mencionadas - fueran oficiales o no- se hablaba de la celebración de concursos o exposiciones, algo que por otro lado se puede explicar por la tendencia que había en estas publicaciones de no referir información de actividades concretas al quedarse inmediatamente desfasadas. Entre estas últimas cabría mencionar aquellas otras muestras y exposiciones organizadas por la Academia independientemente de los premios generales. Aunque no ha sido objeto de esta investigación el estudio de estos acontecimientos, mucho más dispersos, merece la pena anotar que debieron ser más frecuentes de lo que pensamos. Por citar solo dos, sabemos por ejemplo que, a similitud de los premios generales, en alguna ocasión se llegaron a mostrar al público los trabajos realizados por los alumnos para optar a las denominadas ayudas de costas, como las que se convocaron con motivo de los premios mensuales de enero de 1777 entre los discípulos de arquitectura, mencionadas por Ponz en su Viaje de España al hablar de los avances que estaba experimentando esta disciplina en el conjunto del país:

Los jóvenes dedicados a esta nobilísima arte, asistentes a la Real Academia de S. Fernando, corroboran nuestra esperanza, manifestándolo frecuentemente con repetidas muestras de su esmero. El público lo pudo conocer en los trabajos que presentaron, y estuvieron expuestos a su vista por espacio de quince días en las sa-

42 Joseph Townsend, Viaje por España en la época de Carlos III (1786-1787), Madrid, Ediciones Turner, 1988, págs. 115-116. El prudente silencio de Townsend al no entrar a valorar las colecciones artísticas contrasta con el elocuente testimonio de otro viajero inglés que tuvo la oportunidad de visitar, en diciembre de 1787, «los apartamentos de la Academia»: si bien reconocía el mérito a «la valiosísima colección de reproducciones de serenas y graciosas obras antiguas», calificaba el resto de «mamarrachos feroces e indiscretos, obra de artistas españoles modernos»; William BECKFoRD, Un inglés en la España de Godoy (cartas españolas), Madrid, Taurus, 1966, pág. 97. 
las de la Academia, desde el 8 de marzo último, ejecutados con motivo del premio que se propuso en primero de enero antecedente ${ }^{43}$.

Otras veces, las exposiciones respondían a peticiones expresas de la corona, como cuando el monarca quiso en 1778 "promover el ejercicio de la Escultura en los asuntos más dignos de su R. ${ }^{1}$ memoria, y de la gratitud y honor nacional», ordenando que la Academia propusiese, preferentemente a «los Directores y Tenientes de aquella Arte, formar un modelo de cuatro pies de alto que represente a caballo al S. ${ }^{\text {or }}$ Felipe V. Augusto Padre de S. M. sin incluir en la medida prescrita el zócalo, o basa, y debiendo ser armada la figura» ${ }^{44}$. A la petición del encargo respondieron los directores Juan Pascual de Mena y Robert Michel, los tenientes directores Manuel Álvarez y Francisco Gutiérrez, así como el académico de mérito Juan Adán, antiguo pensionado en Roma. Tal y como se informaba en las memorias de la Academia publicadas en la Distribución de premios del año 1781, «concluidos dichos modelos, que fueron cinco, y habiéndoles visto el Público, como S. M. quería, dispuso el Señor Protector, que se llevasen al Casón del Retiro, donde con mucho agrado les vieron el Rey y Príncipe nuestros Señores en 12 de julio de $1780{ }^{45}$.

De todas estas iniciativas ha quedado una memoria frágil y enormemente dispersa. Pese a ello, la aparición de nuevos títulos de prensa durante las dos últimas décadas de la centuria contribuyó a dar más visibilidad a la labor de la Academia, así como a impulsar gradualmente una incipiente crítica en los debates de la opinión pública que, al menos, parecía demostrar la existencia de un público cada vez más interesado en las bellas artes ${ }^{46}$. Un empuje significativo en las acciones destinadas a dar a conocer los progresos y actividades de la propia Academia fue la petición que Pedro Pablo Trullench y Joaquín Ezquerra remitieron a principios de 1784 al secretario de la institución ${ }^{47}$,

${ }^{43}$ Ponz, Viaje de España, 1778, t. VII, pág. xv. Sobre el sistema de ayudas de costas y sus premios, vigente entre 1768 y 1792, véanse Bédat, La Real Academia de Bellas Artes, págs. 206-211, y NAVARRETE Martínez, La Academia de Bellas Artes y la pintura, pág. 245.

44 ARABASF, «Actas de sesiones particulares y de gobierno de la Real Academia de Bellas Artes de San Fernando, 1757-1854», Junta ordinaria de 3 de octubre de 1778, Sig. 3-84, fols. 105r-105v.

45 Distribución de los premios concedidos [...] en la Junta pública de 14 de julio de 1781, Madrid, Joaquín Ibarra, 1781, págs. 3-4.

46 Daniel Crespo Delgado, «Diario de Madrid 1787-1788: de cuando la historia del arte devino una cuestión pública», Goya. Revista de Arte, 319-320 (2007), pp. 246-258.

47 Inmaculada UrZainQui MiQueleiz, «Los redactores del "Memorial Literario" (1784-1808)», Estudios de historia social, núm. 52-53 (1990), págs. 501-516. 
[...] cuyo contenido era que habiéndose propuesto publicar una obra periódica con el título de Memorial Literario, Instructivo y Curioso de la Corte de Madrid, y que siendo uno de sus artículos dar razón del adelantamiento de los Discípulos que concurren a estos estudios, y de los premios mensuales que se reparten a los beneméritos, a fin de promover con su noticia la aplicación a las Nobles Artes, etc., suplicaban se sirviese mandar la Academia comunicarle las noticias que sobre este punto juzgase convenientes ${ }^{48}$.

Ya en su primer número, el Memorial Literario incluyó una breve pero completa nota informativa sobre la corporación, considerada «uno de los establecimientos más útiles que hay en la nación» en el cultivo, promoción y difusión de las nobles artes. Allí se explicaba la composición y estructura de su gobierno, los distintos tipos de miembros que existían y sus principales actividades de enseñanza $^{49}$. En los siguientes números, y una vez atendida la solicitud inicial de sus editores por parte de la Academia, se dio puntual noticia de los premios mensuales. En la entrega correspondiente al mes de agosto, se insertó la crónica más completa de cuantas se publicaron en toda la segunda mitad del siglo XVIII sobre la ceremonia de los premios generales y, particularmente, de la exposición abierta a continuación. Los visitantes no solo pudieron ver «las obras premiadas, sino otras remitidas desde Roma, y por algunas otras personas [...] por espacio de más de 15 días después de la función de los premios, prueba de la inclinación y complacencia con el que el público de Madrid ha mirado dichas obras». En respuesta a esa inclinación, pareció «justo acordarle en este paraje lo que representaban, y los nombres de los que las habían hecho», dando a conocer así al resto de artistas que exhibían obras fuera del concurso. Es muy posible que la inserción de esta relación, inédita hasta entonces, viniese motivada por la participación en la exposición del infante don Gabriel, que había remitido dos años antes «dos cabezas de Santos Apóstoles, dibujadas de lápiz negro, y rojo en el tamaño del natural», dando pie a su ingreso como académico de mérito en la pintura ${ }^{50}$. Tal vez por ese mismo motivo la información se incluyó a modo

\footnotetext{
48 ARABASF, «Actas de sesiones particulares y de gobierno de la Real Academia de Bellas Artes de San Fernando, 1757-1854», Junta particular de 4 de abril de 1784, Sig. 3-84, fol. 274v.

49 Memorial literario, instructivo y curioso de la corte de Madrid, enero de 1784, págs. 21-22. La obra contó con el apoyo del Gobierno para facilitar su difusión más allá de la capital, llegando incluso a abrir suscripciones fuera de la Península; Elisabel Larriba, El público de la prensa en España a finales del siglo XVIII (1781-1808), Zaragoza, Prensas de la Universidad de Zaragoza, págs. 85-88.

50 Memorial literario, instructivo y curioso de la corte de Madrid, agosto de 1784, págs. 24-41; la relación de obras complementarias a los trabajos de los premiados se abría con la referencia a los trabajos del infante, seguida de «Obras de pintura de los Pensionados de S. M. en Roma, enviadas últimamente», «Obras de Escultura» y «Obras de Arquitectura»; págs. 36 y ss.
} 
de nota en la Distribución de premios del año 1784, lo que también supuso una excepcionalidad que no se volvería a repetir ${ }^{51}$.

La consolidación de un público estable en las exposiciones de la Academia de Bellas Artes de San Fernando tuvo su punto álgido en la última década del siglo. En las actas de la Distribución de premios de 1790, se celebraba cómo, durante los últimos años, «el idioma de las artes se había extendido entre toda clase de personas, aún entre los que desconocían antes sus bellezas» por todo el país, gracias a la apertura continuada en distintas provincias de otras academias y escuelas de dibujo, así como a los esfuerzos realizados en materia editorial, al publicar y hacer traducir un completo catálogo de tratados teóricos y ensayos, sobre el que «el público ha formado ya su juicio sobre el respectivo mérito» ${ }^{52}$. A la difusión de estos libros contribuyó igualmente la «Real orden de S. M. dirigida a que los libros, estampas y dibujos pertenecientes a las Artes, que la Academia hubiese adquirido, se franqueasen al público para común utilidad y beneficio de los Profesores y aficionados», estableciéndose así una biblioteca pública a la que se podía acudir «los martes, miércoles y viernes de cada semana, siempre que no sean festivos, desde las nueve hasta la una», dándose el aviso en la prensa «para noticia de los profesores y amantes del estudio de las bellas artes» ${ }^{53}$.

Sin entrar a valorar el impacto que pudo tener la apertura de la biblioteca o el nivel real de conocimientos de aficionados y curiosos, lo cierto es que la asistencia a las exposiciones de los premios siguió creciendo, aunque en muchos casos se tratara de un público que concebía su visita como una extensión más de sus paseos por la ciudad ${ }^{54}$. A la vista del crecimiento de asistentes, en la Junta particular de 3 de septiembre de 1793 se trató la siguiente propuesta de futuro a iniciativa de Bernardo Iriarte:

${ }^{51}$ Distribución de los premios concedidos [...] en la Junta pública de 17 de julio de 1784, Madrid, Joaquín Ibarra, 1784, págs. 83-84. Es bastante probable que la decisión de incorporar la información se hiciera en el último momento, debiendo ajustar el texto al espacio disponible con un cuerpo menor de letra, quizás por estar ya impresa la publicación.

52 Distribución de los premios [...] de 1790, págs. 9-10.

53 Mercurio de España, febrero de 1794, págs. 306-307. La biblioteca abrió sus puertas el 14 de enero de 1794, una vez definidos en los meses previos el nombramiento de un bibliotecario, el diseño de su reglamento y la ordenación de sus fondos; José Antonio Domínguez SaLAzar, «La Real Academia de Bellas Artes en sus comienzos (1744-1844). El bicentenario de la apertura al público de su biblioteca y archivo», en Obras maestras de la Real Academia de San Fernando. Su primer siglo de historia, Madrid, Real Academia de Bellas Artes de San Fernando, 1994, págs. LIII-LXIV; pág. LVI.

54 Se trataría, en ambos casos, de una experiencia visual similar, al menos para aquellas gentes sin un interés particular en las obras expuestas ni verdadera afición a las bellas artes, pero que concebían su visita como un espectáculo que daba continuidad al paseo por las calles, el cual se podía concebir igualmente como una pintura con figuras vivas, como propone sugerentemente Eugenia Afinoguénova, El Prado. La cultura y el ocio (1819-1939), Madrid, Cátedra, 2019, pág. 67. 
El S. ${ }^{\text {or }}$ Viceprot. ${ }^{\text {or }}$ hizo presente el gran número de gentes de todas clases, que han concurrido en este trieno a ver la Academia y las obras de los opositores al Concurso Gen. ${ }^{1}$ de Premios en los once días que han estado abiertas sus salas: y propuso que para excitar el gusto y afición a las Nobles Artes, y la estimación y concepto del Instituto de la Academia, convendría (si la Junta lo tenía a bien) que todos los años durante las vacaciones estuviese por quince días abierta la Academia y franca la entrada al Público, con facultad a los Profesores, Discípulos y aficionados de exponer en ella las obras que hubiesen ejecutado. La Junta aplaudió el celo del S. ${ }^{\text {or }}$ Viceprot. ${ }^{\text {or }}$ y acordó que se llevase a cabo la propuesta de S. Ilma. ${ }^{55}$.

El acuerdo, que desligaba por primera vez la organización de las exposiciones a la de los premios generales, se materializó un año más tarde, y contó entre sus primeros y más ilustres visitantes «a los Reyes nuestros Señores, acompañados de las Señoras Infantas Doña María Amalia y Doña María Luisa, del Sr. Infante D. Antonio, y del Sr. Príncipe de Parma D. Luis», recibidos por Manuel Godoy en calidad de Protector. A diferencia de la visita real de 1775, limitada a dar a conocer las salas de estudio, la familia real pudo en esta ocasión admirar el crecimiento de las colecciones artísticas y antigüedades que se conservaban en la Academia, «que SS. MM. han concurrido a ennoblecer también con obras ejecutadas de su propia mano, que la Academia conserva y tiene siempre a la vista en lugar preminente y decoroso ${ }^{56}$. El mismo periódico informaba unas páginas más adelante sobre la decisión de que estuvieran abiertas «todos los años durante el número de los días que se señale, las salas del cuarto principal, admitiendo a todas las personas inteligentes y de buen gusto que acudan a ver la copiosa y estimable colección de estatuas sacadas de lo antiguo, y demás preciosidades que posee», informando igualmente sobre días de apertura y horarios ${ }^{57}$. La noticia, finalmente, servía como aviso a

[...] los profesores y personas aficionadas que hayan dedicado su aplicación y talento a cultivar las tres Nobles Artes, y tengan obras propias que quieran exponer en la Academia para darlas a conocer a los inteligentes y amantes de las Artes,

55 ARABASF, «Actas de sesiones particulares y de gobierno de la Real Academia de Bellas Artes de San Fernando, 1757-1854», Junta particular de 3 de septiembre de 1793, Sig. 3-124, fol. 229r.

56 Mercurio de España, julio de 1794, págs. 336-337.

57 «En el presente año estará abierta la Academia desde el 21 hasta el 31 del corriente mes de Julio, excluyendo los festivos, de las 10 a las 12 de la mañana, y de las 4 a las 7 por la tarde»; Mercurio de España, julio de 1794, págs. 347-348. 
[quienes] podrán enviar al Conserje las pinturas, esculturas, dibujos, \&c. que hayan ejecutado, acudiendo después a recogerlas ${ }^{58}$.

La falta de registros impide hacer un cálculo, siquiera aproximado, del número real de visitantes que frecuentaron las exposiciones en los días de apertura de verano durante estos primeros años, aunque es fácil imaginar que para los auténticos aficionados — casi siempre personas distinguidas que disponían de contactos y recursos—no debía resultar nada difícil visitar las salas de estudio y sus colecciones en cualquier momento del año, máxime si se trataba de viajeros extranjeros, como hemos tenido ocasión de comprobar. En cualquiera de los casos, es evidente que, a finales de siglo, la imagen que se proyectaba de la institución en la prensa, guías y otras publicaciones había empezado a cambiar definitivamente. Un último ejemplo que puede servir de referencia es el de las Noticias varias y curiosas de Madrid que, entre 1791 y 1797, publicó Ángel Valero anualmente. Al igual que otras guías publicadas con anterioridad, como la ya citada Madrid en la mano, la primera mención que se hace de la Academia se encuentra recogida entre los establecimientos de enseñanza, identificándola como «las [escuelas] de dibujo y demás correspondientes a las tres nobles artes, c. de Alcalá en la casa donde está el Gabinete de Historia Natural» ${ }^{59}$. Un año más tarde, sin embargo, su autor la incluía ya en la «Noticia de los templos, palacios, casas, teatros, jardines y cosas más dignas de la curiosidad pública que hay en Madrid» para «ocupar la curiosidad de los naturales y forasteros de esta imperial y coronada villa» ${ }^{60}$, haciendo indicar en una nota a pie de página un comentario que, sin duda alguna, venía a dar cuenta del prestigio alcanzado en la opinión pública tras la decisión de abrir las puertas al público en las exposiciones de verano:

La buena disposición y simetría con que se han colocado últimamente las excelentes pinturas, estatuas, bustos, bajo relieves y demás hacen muy agradable vista, y llenan el digno objeto de esta casa, que desde la escalera empieza a manifestar las preciosidades que contiene ${ }^{61}$.

58 Mercurio de España, julio de 1794, págs. 347-348. Para un conocimiento más a fondo de las dinámicas de organización y la puesta en marcha de estas nuevas exposiciones, véase NaVARRETE MaRTínEz, La Academia de Bellas Artes y la pintura, págs. 297-302.

59 Ángel VALERo, Noticias varias y curiosas de Madrid para el año de 1793, Madrid, Imprenta de Benito Cano, 1793, pág. 109.

60 Ángel VAlero, Noticias varias y curiosas de Madrid para el año de 1794, Madrid, Imprenta de Benito Cano, 1794, págs. 78-82

61 El comentario sobre las habitaciones se mantuvo en los mismos términos en la edición de 1795 (pág. 76), eliminándose en las ediciones de 1796 y 1797, último año en que se publicó la colección. 
La renovada imagen de la Academia, espacio ya reconocido entre las curiosidades que debían visitar naturales y forasteros a finales de siglo, contrastó, sin embargo, con la pobreza de un público incapaz de establecer un diálogo a través de la crítica en los debates de opinión ${ }^{62}$. Esto impide conocer el impacto de las exposiciones entre sus visitantes, o la apreciación real que estos últimos hicieron de las obras que cada verano adornaban sus salones, un silencio del que se lamentaba un lector apodado el «Español Provinciano» en una extensa carta dirigida al director del Diario de Madrid, escrita en estos términos:

Yo, pobre de mí, esperaba que como en mi tierra, se hiciese también en Madrid una mención honorífica en los periódicos de lo que tantos sudores y desvelos cuesta a los profesores de las bellas artes; y que dejando intactas las obras premiadas por la Academia se hablase de las demás con una crítica juiciosa que demostrase su mérito, alentase a los alumnos, diese ánimo a los maestros [...] Mis esperanzas han sido vanas: el tiempo ha pasado y nadie ha desplegado sus labios para hablar una palabra, ni tomado la pluma para escribir dos renglones ${ }^{63}$.

Aunque esta primera misiva dio pie a un fructífero intercambio de opiniones en los meses posteriores, la realidad descrita se mantuvo por lo general durante, al menos, los años anteriores a la Guerra de la Independencia. En consecuencia, las noticias publicadas sobre las exposiciones en la prensa se limitaron a dar aviso de su apertura, anunciar la convocatoria de los premios o convocar a los artistas interesados en exponer obra propia. Así pues, para encontrar una respuesta de cierto calado por parte del público habría que esperar ya a las primeras décadas del siglo XIX, una vez terminado el conflicto, momento en el que terminarían por definirse en España las bases de su identidad como sujeto colectivo ${ }^{64}$.

62 Para una revisión sobre el alcance de la crítica en este periodo, sus agentes y las distintas esferas en las que actuó, como la de las exposiciones, véase Andrés UBEDA De los Cobos, Pensamiento artístico español del siglo XVIII. De Antonio Palomino a Francisco de Goya, Madrid, Museo Nacional del Prado, 2001, págs. 99-129.

63 Diario de Madrid, 12/09/1802, núm. 255, págs. 1029-1032.

64 Véase al respecto Álvaro Molina, «Los públicos de las bellas artes en los orígenes del Museo del Prado», en Joaquín Álvarez Barrientos y Daniel Crespo Delgado (eds.), Museo del Prado, 1819, Madrid, Museo Nacional del Prado, 2020 [en prensa]. 